\title{
Istraživanje rasta i rodnosti sorti bresaka u ekološkim uvjetima Istre
}

\author{
Investigation of growth and yield of peach varieties \\ in ecological conditions of Istria
}

\section{Miljković}

\section{SAŽETAK}

Istraživan je rast i rodnost 20 sorti bresaka različitog vremena zrenja, a uzgojenih u obliku palmete u uvjetima suhog gospodarenja. Istraživanjima je utvrđeno da su sve sorte u ekološkim uvjetima Istre postigle dobru vegetativnu razvijenost u 5. vegetaciji. Prema bujnosti su sorte podijeljene u tri skupine: vrlo bujne s promjerom debla iznad 12 $\mathrm{cm}$, bujne s promjerom debla od $10-12 \mathrm{~cm}$ i srednje bujne s promjerom debla ispod 10 $\mathrm{cm}$. Među vrlo bujne spadaju: Springold, Merrill Gem Free, Springcrest, Armgold, Fairtime, Fayette, i Red Top. Među bujne spadaju: Filette, Redcap, Early Red, Early Redhaven, Sentinel, Regina, Redhaven i Suncrest, a u srednje bujne: Collins, Southland, Glohaven Cresthaven i Redskin. Nešto veću rodnost postigle su sorte: Sentinel, Early Redhaven, Redhaven, Regina, Early Red, Filette i Cresthaven, a srednji sorte: Red Top, Glohaven, Redcap, Merrill Gem Free, Collins, Fayette, Redskin, Suncrest, Fairtime i Southland, dok su najmanji prirod postigle sorte Springold, Springcrest i Armgold.

Ključne riječi: breskva, rast, rodnost, ekološki uvjeti

\section{ABSTRACT}

Investigation was carried out for twenty peach varieties with different time of harvest in dry farming system. All trees were in classic palmette training. Based on the investigation it was determined that all varieties have achieved good vegetative growth in 5th vegetation. According to vigor varieties can be divided in three categories: very vigorous with three diameter above $12 \mathrm{~cm}$, vigorous with diameter of $10-12 \mathrm{~cm}$ and medium vigorous with diameter less than $10 \mathrm{~cm}$. Very vigorous are: Springold, Merrill Gem Free, Springcrest, Armgold, Fairtime, Fayette and Red Top. Vigorous are Filette, Redcap, Early Red, Early Redhaven, Sentinel, Regina, Redhaven and Suncrest. Medium vigorous are Collins, Southland, Glohaven Cresthaven and Redskin. Somewhat greater yield has been achieved by varieties Sentinel, Early Redhaven, Redhaven, Regina, Early Red, Filette and Cresthaven medium yield by varieties Red Top, Glohaven, Redcap, Merrill Gem Free, Collins, Fayette, Redskin, Suncrest, Fairtime and Southland and lowest yield by varieties Springold, Springcrest and Armgold.

Key words: peach, growth, yield, ecological condition 


\section{UVOD}

Za potrebe stalno rastuće turističke privrede na zapadnoj obali Istre veliko značenje ima opskrba kvalitetnim plodovima bresaka. Poznato je da se u toplijem mediteranskom području postiže znatno bolja kvaliteta plodova sorti bresaka. Također je poznato da plodovi breskve lošije podnose duži transport i da se ne mogu duže čuvati u hladnjači. Važno je da se potrošačima osigura svježe i kvalitetno voće. Jasno je da za potrebe turista i domaćeg stanovništva u obalno području Istre treba osigurati vlastitu proizvodnju bresaka u neposrednoj blizini. Napomenimo još da se u tom području za vrijeme turističke sezone postižu dobre prodajne cijene i izvrstan ekonomski uspjeh u uzgoju bresaka. Velik je broj kvalitetnih sorti koje dozrijevaju tijekom čitave turističke sezone, pa se može osigurati uvijek svježe plodove proizvedene u neposrednoj blizini tržišta. Da se pridonese boljem poznavanju aktualne problematike podignut je breskvik sa više sorti prema vremenu zrenja. Selekcionari u proizvodnju često uvode nove bolje sorte, koje zamjenjuju lošije istog vremena zrenja. Neke se sorte vrlo dugo održe zbog svojih dobrih gospodarskih svojstva i prilagodbe ekologijskim uvjetima proizvodnog područja. U breskviku je na u petoj vegetaciji istraživana vegetativna razvijenost, rodnost i kvaliteta plodova 20 sorti različitog vremena zrenja, a u 6 . vegetaciji 12 sorti bresaka.

\section{OBJEKT ISTRAŽIVANJA I METODIKA RADA}

Istraživanja su obavljena u voćnjaku na objektu Špinel kraj Umaga. Sorte bresaka, cijepljene na podlozi sjemenjaka vinogradske breskve, posađene su u jesen 1975. godine na razmak 5 x 4,5 m, a uzgojene u obliku klasične pravilne palmete s kosim granama. Istraživanja su obuhvatila slijedeće sorte: Filette, Armgold, Springold, Springcrest, Merrill Gem Free, Early Red, Collins, Early Redhaven, Redcap, Sentinel, Redhaven, Regina, Redtop, Southland, Glohaven, Suncrest, Cresthaven, Fairtime, Redskin i Fayette. Istraživanje vegetativne razvijenosti provedeno je mjerenjem promjera debla, promjera skeletnih grana $\mathrm{u}$ sve tri etaže i visinu stabala na kraju 5. vegetacije. Istraživanje rodnosti obuhvaća prirod po stablu varijacijski koeficijent, prosječnu masu ploda, prirod po hektaru i vrijeme berbe. Rast i rodnost sorti bresaka utvrđen je na isti način i u 6. vegetaciji za sorte: Redcap, Sentinel, Redhaven, Regina, Redtop, Southland, Glohaven, Suncrest, Cresthaven, Fairtime, Redskin i Fayette. Za istraživanje je slučajnim rasporedom odabrano po 5 stabala u 3 repeticije, odnosno istraživanja su obuhvatila za svaku sortu po 15 stabala. Rezultati 
istraživanja rodnosti po stablu obrađeni su varijaciono statistički analizom varijance, a izračunat je i varijacijski koeficijent. U 5. vegetaciji stabala istraživanja su obuhvatila 20 sorti, a u 6 . vegetaciji 12 sorti.

Voćnjak se nalazi na zapadnoj obali Istre, gdje je izražena jadranska klima. Srednja godišnja temperatura iznosi $14,5^{\circ} \mathrm{C}$. Srednja mjesečna temperatura u proljeće iznosi oko $12{ }^{\circ} \mathrm{C}$, tijekom ljeta (VI, VII i VIII mjesec) oko $21{ }^{\circ} \mathrm{C}$, u jesen oko $12{ }^{\circ} \mathrm{C}$, a tijekom zime oko $5,7^{\circ} \mathrm{C}$. Srednja godišnja količina padalina iznosi oko $920 \mathrm{~mm}$, od čega tijekom proljeća padne oko $166 \mathrm{~mm}$, ljeta $221 \mathrm{~mm}$, jesen $291 \mathrm{~mm}$, a zimi $235 \mathrm{~mm}$. U prosjeku za duže razdoblje količina oborina u periodu vegetacije iznosi oko $490 \mathrm{~mm}$, a u periodu mirovanja vegetacije 535 mm. Najsušniji mjeseci su: svibanj, lipanj, srpanj i kolovoz.

$\mathrm{U}$ to vrijeme prema proračunu po metodi Thorntweit-a nedostaje u svibnju oko $90 \mathrm{~mm}$, lipnju oko $60 \mathrm{~mm}$, srpnju oko $50 \mathrm{~mm}$ i kolovozu oko $70 \mathrm{~mm}$ padalina. U voćnjaku je uzgoj bresaka u suhom gospodarenju, jer zbog nedostatka raspoložive vode nije provođeno natapanje. Tlo je u voćnjaku ilovaste teksture, neutralne do slabo alkalne reakcije $\left(\mathrm{pH} \mathrm{u} \mathrm{H}_{2} \mathrm{O}\right.$ iznosi 6,90, a u $\mathrm{n} / \mathrm{KCl} 5,60)$ s $3,8 \%$ humusa, i $2,7 \% \mathrm{CaCO}_{3}$. Tlo je održavano u stanju obrade. Redovito je obavljana zaštita.

\section{REZULTATI ISTRAŽIVANJA}

Rezultati istraživanja vegetativne razvijenosti stabala na karaju 5. vegetacije izneseni su na tablici 1 . Sve su sorte u prvih 5 godina postigle dobru vegetativnu razvijenost. $U$ odnosu na bujnost sorte se mogu podijeliti na vrlo bujne, bujne i srednje bujne. U skupinu vrlo bujnih spadaju sorte s promjerom debla iznad $12 \mathrm{~cm}$. U ovu skupinu spadaju sorte: Springold, Merrill Gem Free, Springcrest, Armgold, Fairtime, Fayette i Red Top.

U skupinu sorti bujnog rasta razvrstane su sorte s promjerom debla od 10 do $12 \mathrm{~cm}$. Ovoj skupini pripadaju sorte: Filette, Redcap, Early Red, Early Redhaven, Sentinel, Regina, Redhaven i Suncrest. U skupinu srednje bujnih spadaju sorte s promjerom debala ispod $10 \mathrm{~cm}$. To su sorte: Collins, Southland, Glohaven, Cresthaven i Redskin. Najveću bujnost postigla je sorta Springold, a najmanju sorta Redskin. Sve su sorte do kraja pete vegetacije dobro razvije tri etaže skeletnih grana i zadovoljavajuću visinu stabala. 
Tablica 1.: Vegetativna razvijenost sorti bresaka na kraju 5. vegetacije

Table 1: Vegetative growth of peach varieties at the end of 5 th vegetation

\begin{tabular}{|c|c|c|c|c|c|c|c|}
\hline \multirow{3}{*}{$\begin{array}{c}\text { Sorta } \\
\text { (Variety) }\end{array}$} & \multicolumn{5}{|c|}{ Promjer u cm (Diameter in $\mathrm{cm}$ ) } & \multirow{2}{*}{\multicolumn{2}{|c|}{$\begin{array}{c}\text { Visina } \mathrm{u} \mathrm{cm} \\
\text { (Height in } \mathrm{cm} \text { ) }\end{array}$}} \\
\hline & \multirow{2}{*}{$\begin{array}{c}\text { Deblo } \\
\text { (trunk) }\end{array}$} & \multirow{2}{*}{$\begin{array}{l}\text { Centralna os } \\
\text { (central } \\
\text { axis) }\end{array}$} & \multicolumn{3}{|c|}{$\begin{array}{c}\text { Skeletne grane } \\
\text { (Skeleton branch) }\end{array}$} & & \\
\hline & & & $\begin{array}{l}\text { I etaža } \\
\text { (étage) }\end{array}$ & $\begin{array}{c}\text { II } \\
\text { etaža } \\
\text { (étage) }\end{array}$ & $\begin{array}{c}\text { III } \\
\text { etaža } \\
\text { (étage) }\end{array}$ & $\begin{array}{c}\text { Deblo } \\
\text { (trunk) }\end{array}$ & $\begin{array}{l}\text { Centralna os } \\
\text { (central axis) }\end{array}$ \\
\hline Filette & 11,7 & 7,6 & 6,5 & 3,6 & 2,3 & 42 & 303 \\
\hline Armgold & 12,8 & 8,3 & 7,4 & 4,3 & 2,7 & 54 & 315 \\
\hline Springold & 15,1 & 9,8 & 8,5 & 4,5 & 3,8 & 45 & 325 \\
\hline Springcrest & 13,4 & 9,1 & 7,5 & 4,4 & 2,7 & 47 & 311 \\
\hline Merrill Gem Free & 13,6 & 9,3 & 7,4 & 4,6 & 3,1 & 45 & 314 \\
\hline Early Red & 10,7 & 7,2 & 6,3 & 3,4 & 3,6 & 37 & 292 \\
\hline Collins & 9,9 & 6,7 & 5,7 & 3,5 & 2,8 & 54 & 269 \\
\hline Early Redhaven & 10,7 & 7,4 & 6,5 & 4,2 & 2,1 & 45 & 294 \\
\hline Redcap & 11,4 & 7,8 & 6,9 & 4,0 & 2,4 & 49 & 324 \\
\hline Sentinel & 11,8 & 8,3 & 6,8 & 4,4 & 3,5 & 51 & 313 \\
\hline Redhaven & 10,5 & 7,6 & 6,4 & 4,3 & 2,8 & 45 & 296 \\
\hline Regina & 11,3 & 7,9 & 6,7 & 3,9 & 2,5 & 42 & 323 \\
\hline Redtop & 10,1 & 7,4 & 5,8 & 4,0 & 2,3 & 42 & 298 \\
\hline Southland & 9,5 & 6,6 & 5,2 & 3,6 & 2,2 & 52 & 268 \\
\hline Glohaven & 8,4 & 6,0 & 5,0 & 3,3 & 2,2 & 53 & 246 \\
\hline Suncrest & 11,5 & 7,7 & 6,7 & 4,1 & 2,3 & 52 & 287 \\
\hline Cresthaven & 8,9 & 6,1 & 5,5 & 3,0 & 2,1 & 47 & 264 \\
\hline Fairtime & 12,5 & 8,4 & 7,3 & 4,0 & 3,0 & 47 & 320 \\
\hline Redskin & 8,1 & 6,0 & 5,3 & 3,1 & 2,5 & 60 & 234 \\
\hline Fayette & 12,6 & 7,9 & 6,8 & 4,4 & 2,4 & 42 & 300 \\
\hline
\end{tabular}

Rezultati istraživanja rodnosti po stablu, varijacijskog koeficijenta, priroda po hektar i prosječne mase plodova i vremena berbe u 5 . vegetaciji izneseni su na tablici 2, a u 6. vegetaciji na tablici 3. Najveći prirod u 5. vegetaciji postigle su: Filette, Early Red i Early Redhaven. Utvrđena je signifikantno opravdana razlika za količinu priroda između ove tri sorte i sorata: Springold, Armgold, Springcrest, Regina, Redtop, Redskin i Fayette. Najniži prirod postigle su sorte: Springold, Armgold, Springcrest. Osim toga za ove sorte ustanovljen je najveći varijacijski koeficijent. Između ove tri sorte i ostalih istraživanih sorti utvrđena je opravdana razlika. Podjednak prirod iznad $30 \mathrm{~kg} / \mathrm{stablo}$ postigle su sorte: Merrill Gem Free, Collins, Redcap, Sentinel, Redhaven, Cresthaven, Fairtime i Southland. Niži prirod od $30 \mathrm{~kg} /$ stablo postigle su sorte: Glohaven, Regina, Red Top, Suncrest, Redskin, i Fayette. 
I. Miljković: Istraživanje rasta i rodnosti sorti bresaka u ekološkim uvjetima Istre

Tablica 2.: Rodnost sorti bresaka u kg/stablo, dt/ha, prosječna masa ploda i vrijeme berbe u 5. vegetaciji (1980)

Table 2: Yield of peach variety in $\mathrm{kg} / \mathrm{tree}, \mathrm{dt} / \mathrm{ha}$, average weight of fruit and time of harvest at the end of $5^{\text {th }}$ vegetation (1980)

\begin{tabular}{|c|c|c|c|c|c|}
\hline $\begin{array}{c}\text { Sorta } \\
\text { (Variety) }\end{array}$ & $\begin{array}{c}\text { Prirod } \\
\mathrm{kg} / \mathrm{stablo} \\
\text { (Yield } \\
\mathrm{kg} / \text { tree) }\end{array}$ & $\begin{array}{c}\text { Varijacijski } \\
\text { koeficijent } \\
\text { (Coefficient } \\
\text { of variation) } \\
\text { - cv }\end{array}$ & $\begin{array}{l}\text { Težina ploda } \\
\mathrm{u} g \text { (Weight } \\
\text { of fruit in } \mathrm{g} \text { ) }\end{array}$ & $\begin{array}{c}\text { Prirod } \\
\text { (Yield) } \\
\text { dt/ha }\end{array}$ & $\begin{array}{l}\text { Vrijeme berbe } \\
\text { (Time of harvest) }\end{array}$ \\
\hline Filette & 36,5 & 26,0 & 100 & 16,21 & 23. VI - 8. VII \\
\hline Armgold & 19,2 & 44,0 & 90 & 8,52 & 23. VI - 2. VII \\
\hline Springold & 12,5 & 32,6 & 84 & 5,55 & 23. VI - 2. VII \\
\hline Springcrest & 17,9 & 34,0 & 90 & 7,94 & 23. VI - 2. VII \\
\hline $\begin{array}{l}\text { Merrill } \\
\text { Gem Free }\end{array}$ & 30,0 & 21,3 & 100 & 13,32 & 9. VII - 16. VII \\
\hline Early Red & 36,6 & 38,1 & 144 & 16,25 & 16. VII - 25. VII \\
\hline Collins & 32,9 & 22,9 & 148 & 14,61 & 16. VII - 22. VII \\
\hline $\begin{array}{l}\text { Early } \\
\text { Redhaven }\end{array}$ & 39,2 & 10,5 & 152 & 17,40 & 21. VII - 24. VII \\
\hline Redcap & 34,4 & 13,7 & 152 & 15,27 & 16. VII - 24. VII \\
\hline Sentinel & 34,3 & 15,4 & 144 & 15,23 & 21. VII - 27. VII \\
\hline Redhaven & 30,7 & 15,2 & 148 & 13,63 & 30. VII - 6. VIII \\
\hline Regina & 26,2 & 5,1 & 136 & 11,63 & 4. VIII - 11. VIII \\
\hline Red Top & 28,7 & 11,4 & 150 & 12,74 & 10. VIII - 15. VIII \\
\hline Southland & 29,9 & 11,4 & 140 & 13,27 & 13. VIII - 22. VIII \\
\hline Glohaven & 29,6 & 17,7 & 130 & 13,14 & 18. VIII - 25. VIII \\
\hline Suncrest & 29,2 & 217 & 144 & 12,96 & 14. VIII - 20. VIII \\
\hline Cresthaven & 30,0 & 14,3 & 180 & 13,32 & 3. IX - 12. IX \\
\hline Fairtime & 30,4 & 24,2 & 140 & 13,50 & 10. VII - 16. VII \\
\hline Redskin & 26,0 & 26,3 & 138 & 11,54 & 22. VIII - 26. VIII \\
\hline Fayette & 25,4 & 13,4 & 160 & 11,54 & 22. VIII - 27. VIII \\
\hline
\end{tabular}

Rezultati istraživanja rodnosti po stablu, varijacijskom koeficijentu, prosječno masi plodova, prirodu po hektaru i vremenu berbe u 6 . vegetaciji izneseni su na tablici 3. 
Tablica 3.: Rodnost sorti bresaka u kg/stablo, dt/ha, prosječna masa ploda i vrijeme berbe u 6. vegetaciji (1981.)

Table 3: Yield of peach variety in $\mathrm{kg} / \mathrm{tree}, \mathrm{dt} / \mathrm{ha}$, average weight of fruit and time of harvest at the end of 6 th vegetation (1981.)

\begin{tabular}{|c|c|c|c|c|c|}
\hline $\begin{array}{c}\text { Sorta } \\
\text { (Variety) }\end{array}$ & $\begin{array}{l}\text { Prirod } \\
\mathrm{kg} / \text { stablo } \\
\text { (Yield } \\
\mathrm{kg} / \text { tree) }\end{array}$ & $\begin{array}{l}\text { Varijacijski } \\
\text { koeficijent } \\
\text { (Coefficient } \\
\text { of variation) } \\
\text { - cv }\end{array}$ & $\begin{array}{l}\text { Težina ploda } \\
\text { u g (Weight } \\
\text { of fruit } \\
\text { in } g \text { ) }\end{array}$ & $\begin{array}{c}\text { Prirod } \\
\text { (Yield) } \\
\text { dt/ha }\end{array}$ & $\begin{array}{l}\text { Vrijeme berbe } \\
\text { (Time of harvest) }\end{array}$ \\
\hline Redcap & 28,3 & 37,7 & 120 & 12,56 & 20. VII - 30. VII \\
\hline Sentinel & 56,6 & 24,0 & 120 & 25,13 & 20. VII - 27. VII \\
\hline Redhaven & 49,1 & 24,7 & 130 & 21,80 & 21. VII - 7. VIII \\
\hline Regina & 47,3 & 22,6 & 112 & 21,00 & 23. VII - 3. VIII \\
\hline Red Top & 31,5 & 24,7 & 126 & 13,99 & 7. VIII - 12. VIII \\
\hline Southland & 32,4 & 16,3 & 136 & 14,38 & 3. VIII - 12. VIII \\
\hline Glohaven & 32,3 & 13,8 & 120 & 14,34 & 15. VIII - 23. VIII \\
\hline Suncrest & 33,0 & 16,6 & 132 & 14,65 & 3. VIII - 17. VIII \\
\hline Cresthaven & 32,4 & 13,4 & 160 & 14,38 & 22. VII \\
\hline Fairtime & 33,7 & 21,6 & 128 & 14,96 & 6. VII - 13. VII \\
\hline Redskin & 31,6 & 16,5 & 140 & 14,03 & 20. VIII - 24. VIII \\
\hline Fayette & 31,2 & 8,6 & 156 & 13,85 & 22. VIII \\
\hline ), $\quad \begin{array}{l}\mathrm{P}=50 \\
\mathrm{P}=10\end{array}$ & $\begin{array}{l}7,03 \\
9,26\end{array}$ & & & & \\
\hline
\end{tabular}

Na tablici vidimo da su u 6. vegetaciji sve istraživane sorte postigle znatno veći prirod nego u 5. vegetaciji. Signifikantno najveći prirod postigla je sorta Sentinel od svih ostalih sorti. Po količini priroda slijede je sorte Redhaven i Regina. Između prve dvije sorte i ostalih istraživanih sorti razlika je statistički opravdana. Podjednak prirod postigle su sorte: Red Top, Southland, Glohaven, Suncrest, Cresthaven, Fairtime, Redskin i Fayette. Najniži prirod dala je sorta Redcap.

\section{RASPRAVA I ZAKLJUČCI}

Usporedbom rezultata istraživanja rodnosti istih sorti, uzgojenih u obliku pravilne palmete, u ekologijskim uvjetima Ravnih Kotara (Medin et al, 1988.) uz primjenu natapanja sa 100 do $200 \mathrm{~mm}$, odnosno 100 do 200 kubičnih metara vode/ha s rezultati dobivenim u uvjetima zapadne obale Istre u uvjetima suhog gospodarenja dolazimo do zaključka da je sortno obilježje došlo do izražaja. 
Tako su sorte Armgold i Springcrest u oba proizvodna područja postigle najniži prirod. Nasuprot tome, sorta Early Redhaven je u 5. vegetaciji u Istri postigla veći prirod od sorte Redhaven, dok je u Ravnim kotarima u visini priroda zaostaje za sortom Redhaven. Sorte Redhaven i Regina postigle su u 6 . vegetaciji najveći prirod, što je u podudarnosti s iskustvom stečenim u Ravnim kotarima. Sorta Santinel daje stabilne prirode, a u 6. vegetaciji je postigla osjetno najveći prirod. Od navedenih sorti za daljnji uzgoj Medin et al. (1988.) predlaže i dalje sorte Early Redhaven, Redhaven, Regina, Red Top, Sacrest $\mathrm{i}$ Fayette. Prema talijanskom iskustvu (E. Bellini et al. 1995.) za mediteransko područje predlažu se i dalje za uzgoj, od sorti koje smo istraživali u Istri slijedeće: Springcrest, Redhaven, Red Top, Glohaven, i Fayette. Bellini E. i Baroni G. (2000.) smatraju da su i dalje, uz velik broj novih sorti, vrlo vrijedne sorte: Springcrest, Redhaven, Red Top, Glohaven, i Suncrest. Liverani A. et al. (2002.) predlažu i dalje za uzgoj sorte: Springcrest, Redhaven, Glohaven, Suncrest, Red Top i Fayette. Bellini et al. (2006.) predlažu, pored niza novih, kao vrijedne sorte za daljnji uzgoj: Springcrest, Red Top, Glohaven i Redhaven. Interesantno je istaći da većina istraživača smatra sortu Springcrest dobrih gospodarskih svojstava općenito, a posebno u odnosu na vrijeme zrenja plodova. U Ravnim kotarima i našim istraživanjima na zapadnoj obali Istre ova sorta nije postigla dobar urod. Spomenimo još da u ekološkim uvjetima Ravnih kotara sorte: Springold, Redhaven, Suncrest i Fayette, uz uvjete natapanja, postižu dobru kvalitetu plodova (Miljković i Iveković, 1995.).

$\mathrm{Na}$ temelju provedenih istraživanja rasta i rodnosti sorti bresaka u ekologijskim uvjetima zapadne obale Istre mogu se izvesti slijedeći zaključci. Sve su istraživane sorte postigle dobru vegetativnu razvijenost. Najveći prirod u uvjetima suhog gospodarenja postigle su sorte: Sentinel, Early Redhaven, Redhaven, Regina, Early Red i Filette, a umjeren sorte: Red Top, Glohaven Fayette, Suncrest, Cresthaven. Fairtime, Southland i Collins Naniži prirod postigle su sorte: Springold, Springcrest i Armgold.

\section{LITERATURA}

BELLINI, E., CARUSO, T., FORLANI, M., INSERO, O., (1995.): Le cultivar di pesco per le aree meridionali. Ricerca e innovazione per la peschicoltura meridionale. p. 147-176.

BELLINI, E., BARONI, G., (2000.): Oriemntamenti varietali peri 1 pesco. La pescicoltura Veronese alle soglie del 2000. p. 141-229. 
BELLINI, E., NENCETTI, V., NATARELLI, L. LIVERANI, A., INSERO, G., (2006.): Pesche giale., L'informatore agrario N. 23. Fruttiferi liste varietali, p. 37-41.

LIVERANI, A., BELlini, E., BRANDI, F., COLOBNO, R., CONTE, L., INESTI G., NENCETTI, V., (2002.) L'informatore agrario - Suplimento N. 1., Liste varietali dei fruttiferi 2002., Pesco (pesche, nettarine e precoche), p. 55-78.

MEDIN, A., (1971.): Prilog poznavanju proizvodnih svojstava nekih sorata bresaka na Poljoprivrednom Kombinatu „Agrozadar“. Jug. voćarstvo, 1718.

MEDIN, A., (1980.): Višegodišnji rezultati u proizvodnji nekih sorata bresaka na PK „Zadar“", Jug. voćarstvo. 53/54.

MEDIN, A., PAPARIĆ, A., LJUBIČIĆ, M., (1985.): Značajna gospodarska svojstva nekih sorti bresaka i nektarina na Poljoprivrednom kombinatu „Zadar“. Jug. voćarstvo, 73/74.

MEDIN, A., SIKIRIĆ M., DRAGUN G., (1988.): Višegodišnji prirod značajnih sorti bresaka i nektarina na Poljoprivrednom kombinatu ,Zadar". Jug. voćarstvo, 22, 84-85, 2-3, p. 223-230.

MILJKOVIĆ, I., 1976: Kloroza bresaka na smeđe karbonatnom tlu u Istri. Agronomski glasnik, Vol. 38: (1-3) p. 43-56.

MILJKOVIĆ, I., IVEKOVIĆ, V., (1995.): Kemijski sastav plodova nekih sorti bresaka u ekološkim uvjetima Ravnih kotara. Agronomski glasnik br. 6, p. 367-380.

\section{Adresa autora - Author's address:}

Prof. dr. sc. Ivo Miljković

10000 Zagreb, Čazmanska 2 